\title{
The Corrosion Behaviour of WC-Co-Ru Alloys in Aggressive Chloride Media
}

\author{
J. H. Potgieter, ${ }^{1,2}$ P. Olubambi, ${ }^{2}$ and S. S. Potgieter-Vermaak ${ }^{3}$ \\ ${ }^{1}$ Centre of Excellence in Strong Materials, School of Chemical and Metallurgical Engineering, University of the Witwatersrand (Wits), \\ Johannesburg 2050, South Africa \\ ${ }^{2}$ Department of Chemical, Metallurgical and Materials Engineering, Tshwane University of Technology, Private Bag X680, \\ Pretoria 0001, South Africa \\ ${ }^{3}$ Division of Chemistry \& Environmental Science, School of Science \& the Environment, Manchester Metropolitan University, \\ Manchester M15 6 BH, UK
}

Correspondence should be addressed to J. H. Potgieter; johannes.potgieter@wits.ac.za

Received 26 September 2013; Revised 8 January 2014; Accepted 9 January 2014; Published 27 February 2014

Academic Editor: Shengshui $\mathrm{Hu}$

Copyright (C) 2014 J. H. Potgieter et al. This is an open access article distributed under the Creative Commons Attribution License, which permits unrestricted use, distribution, and reproduction in any medium, provided the original work is properly cited.

\begin{abstract}
Hardmetals possess excellent wear resistance, making them suitable alloys in several industrial applications. Mine waters with both dissolved chloride and sulphate salts can be severely corrosive and can limit the application of hardmetal tools in the mining industry. $\mathrm{Ru}$ additions to these alloys can refine and improve selected mechanical properties, but its influence on the corrosion resistance is unknown. A series of WC-Co-Ru alloys was evaluated in different chloride containing media to investigate their corrosion resistance. Standard electrochemical corrosion tests, chronoamperometric measurements, and surface analyses with Raman spectroscopy were conducted. An increasing amount of Ru improves the corrosion resistance of all the alloys. The effect is not as dramatic as that observed with stainless steels containing $\mathrm{Ru}$ in corrosive media. In both corrosive media $\mathrm{Ru}$ decreased the cathodic Tafel constant and has a retarding influence on the cathodic part of the corrosion reaction. Raman analyses indicated the presence of tungsten oxide, hydrated tungsten oxide compounds, and $\mathrm{CoO}$ and $\mathrm{Co}_{3} \mathrm{O}_{4}$ formed on the alloy surfaces during the corrosion process.
\end{abstract}

\section{Introduction}

Hardmetals are sintered composites of metal-ceramic powders [1]. They consist of the mixtures of one or more finely divided hard carbides particles, such as tungsten, titanium, tantalum, and vanadium, embedded in a matrix of soft and ductile binding materials such as cobalt, iron, or nickel. These materials are very hard and possess excellent wear resistance, and this make them suitable alloys in several industrial applications, such as cutting tools or seal rings, linings, valves, jet nozzles, saw blades, fluid mixers, and conveyor belt scrapers [2-4]. Since these materials are not only subjected to wear processes in mining applications but are also in contact with chemically aggressive environments, corrosion can play a major role in the degradation of their surfaces and can significantly accelerate wear $[3,5]$. In long-life applications, the corrosion properties of cemented carbides can have a large influence on overall material performance.
Although corrosion resistance is not a prime requirement of hardmetals, this property is very important in its industrial uses [6]. Since the cobalt binder phase is the most susceptible to corrosion in acidic and neutral media, it follows that improvement of the corrosion resistance of the binder will have a major influence on the overall corrosion resistance $[2,7,8]$. In principle, Co-based cemented carbide does not passivate. Aggressive media preferentially attack the binder while the tungsten carbide itself remains immune [9]. After dissolution of the binder, there remains a skeleton of tungsten carbide (WC) at the surface [9]. Corrosion attack proceeds predominantly at locations where the WC phase has fallen out after localized initiation of corrosion has taken place [4].

The few investigations $[4,7,10]$ comparing WC-Co hardmetals in acidic, neutral, and alkaline solutions reveal a steady corrosion rate that decreases with increasing solution $\mathrm{pH}$. At room temperature, cemented carbides show an excellent resistance in basic and neutral aqueous solutions. 
Strong acid solutions such as hydrochloric and sulfuric acid can cause severe corrosion and material degradation. The presence of aggressive chloride ions in the electrolyte solution could cause increasing corrosion rates. Some authors [4, $7,8,10]$ observed that WC-Co alloys typically displayed pseudopassivation behaviour and do not give the activepassive transition one associates with alloys having the ability to undergo passivation when polarised in a corrosive liquid medium.

Several metallic alloy compositions, including ruthenium and rhenium, and the additions of the refractory metal carbides, such as vanadium carbide (VC), chromium carbide $\left(\mathrm{Cr}_{3} \mathrm{C}_{2}\right)$, titanium carbide $(\mathrm{TiC})$, and tantalum carbide $(\mathrm{TaC})$, increase corrosion resistance of cemented carbides [2, 9-13]. Amongst the PGMs, ruthenium or ruthenium alloy additions have been observed to be very effective. Bonjour [14] has shown that the addition of $\mathrm{Ru}$ into a cobalt binder had a stabilizing effect on the WC-Co composite. A considerable amount of research [14-17] has been focused on the change of the mechanical properties of cemented carbides when the $\mathrm{Ru}$ is added to the binder phase. However, limited work has been done to study corrosion behaviour and the comparisons of corrosion rates of such materials in different solutions.

Previously a group of Russian researchers showed that the additions of platinum group metals (PGMs) to chromiumbased alloys cause a spontaneous shift of the corrosion potential towards more noble values, a phenomenon generally known as cathodic modification [18]. Earlier studies on ruthenium additions have focused on its effects on the corrosion behaviour of stainless steels alloys [18-24]. Only one other recent report described the effect of $\mathrm{Ru}$ additions to the corrosion behavior of WC-Co alloys in sulphuric acid solution [25]. It was concluded from this work that ruthenium affects the cathodic Tafel constant $\left(\beta_{c}\right)$ in $1 \mathrm{M} \mathrm{H}_{2} \mathrm{SO}_{4}$, which indicates that it influences the cathodic part of the corrosion reaction. It also appears that $\mathrm{Ru}$ is more effective in improving corrosion resistance than a small vanadium carbide addition. Finally, it was found that ruthenium additions of up to $3 \mathrm{wt} \%$ $\mathrm{Ru}$ increased the corrosion resistance of the WC-Co alloys in acidic media.

There is scope to expand previous investigations to address the lack of data and knowledge in the field of WC-Co-Ru corrosion behaviour in corrosion media and environments containing chloride ions. The main purpose of this current study is to focus on the influence of $\mathrm{Ru}$ additions on the corrosion behaviour of a WC-Co composite in synthetic mine water and sodium chloride, both aggressive chloride containing media. Also included for comparison purposes was a small VC addition to the WC-Co alloy. The new data revealed by this investigation can assist in identifying new areas of application of WC-Co-Ru alloys and extending the current range of uses of this type of hard metals.

\section{Experimental Methods}

2.1. Material Preparation and Manufacturing. The sample manufacturing procedure was described earlier by Bonjour [14]. WC-Co-Ru is usually made by compacting together a
TABLE 1: The chemical composition of the samples.

\begin{tabular}{lc}
\hline Sample identity & Ru additions $(\% \mathrm{~m} / \mathrm{m})$ \\
\hline S1: WC-10 wt $\%$ Co & 0.0 \\
S2: WC-10 wt $\%$ Co & 0.4 \\
S3: WC-10 wt $\%$ Co & 1.0 \\
S4: WC-10 wt $\%$ Co & 1.5 \\
S5: WC-10 wt $\%$ Co & 2.0 \\
S6: WC-10 wt $\%$ Co & 3.0 \\
S7: WC-10 wt $\%$ Co & $0.4 \mathrm{VC}$ \\
\hline
\end{tabular}

layer of $\mathrm{Ru}$ powder (in the range of $17 \mu \mathrm{m}$ mean particle sizes) and a layer of WC-10\% Co mixed and milled powder (normally in the range of $1 \mu \mathrm{m}$ Co and $1 \mu \mathrm{m}$ mean particle size) at the pressure of about $1.5 \mathrm{MPa}$ applied in the direction normal to the Ru/WC-Co interface. The sample is heated to a temperature of approximately $1000^{\circ} \mathrm{C}$ in a tube furnace and kept at that temperature for 24 hours in argon flowing at a rate of $3.33 \times 10^{-5} \mathrm{~m}^{3} \mathrm{~s}^{-1}$. The sample is then sintered in vacuum at $1410^{\circ} \mathrm{C}$ for one hour. The sintered samples were sectioned at the Ru/WC-Co interface by means of a diamond wafer blade. The chemical compositions of the specimens made and used are given in Table 1.

The samples were wet ground using a coarse plate of MD-Allegro with $80 \mu \mathrm{m}$ grit to achieve a flat top polished surface, and then successively on 120,220 , and $1200 \mu \mathrm{m}$ of fine plate of MD-Allegro, with $1200 \mu \mathrm{m}$ giving a smooth surface. Wet grinding was done by using fast-running water in order to prevent excessive accumulation of heat. The top surface was polished with a pan cloth with $3 \mu \mathrm{m}$ followed by a $1 \mu \mathrm{m}$ diamond spray with an extender to obtain a mirror-like surface. The polished surfaces were cleansed in distilled water and etched using Murakami's reagent $\left(10 \mathrm{~g} \mathrm{~K}_{3}\left[\mathrm{Fe}(\mathrm{CN})_{6}\right]+\right.$ $10 \mathrm{~g} \mathrm{KOH}+100 \mathrm{~mL}$ water) at room temperature for $2-3$ minutes. This was followed by a rinse with distilled water [26] to reveal the details of their microstructures. Light pressure was applied throughout all the surface preparation to prevent grain fallout.

2.2. Microstructural Observation. The etched surface was analysed for microstructural features to obtain optical micrographs using an Axiotech microscope (Carl Zeiss AG, Oberkochen, Germany) equipped with an Axio Cam MRc digital camera.

2.3. Scanning Electron Microscopy (SEM). Morphological and qualitative analyses of the samples were performed using scanning electron microscopy (SEM) equipped with energy dispersive spectroscopy (EDX). The SEM provided information on the physical properties and morphology of the materials, while EDX provided information on their chemistry. A JEOL JSM-5700 SEM was used and operated at $20 \mathrm{kV}$. Scanning electron microscopy was undertaken on polished samples in order to determine the microstructures of the as-cast/sintered samples. 
TABLE 2: Chemical composition of synthetic mine water [3].

\begin{tabular}{lc}
\hline Salt type & Concentration $(\mathrm{mg} / \mathrm{L})$ \\
\hline $\mathrm{Na}_{2} \mathrm{SO}_{4}$ & 1237 \\
$\mathrm{MgSO}_{4}$ & 199 \\
$\mathrm{CaCl}_{2}$ & 1038 \\
$\mathrm{NaCl}$ & 1380 \\
\hline
\end{tabular}

2.4. Raman Spectroscopy. In order to identify the thin surface films (corrosion products) at high resolution, Raman spectroscopy was used. A laser source of $\mathrm{Ar}^{+}$was used to capture the scan patterns at room temperature, whereas the image on the surface of the alloy was captured, with a light microscope. The spectrum was collected by directing a continuous laser of $\mathrm{Ar}^{+}(514.5 \mathrm{~nm})$ of a Bruker Senterra Raman spectrometer on the alloy surface. The samples were scanned from 100 to $2500 \mathrm{~cm}^{-1}$ wavenumbers, with a resolution of $4 \mathrm{~cm}^{-1}$.

\subsection{Corrosion Tests}

2.5.1. Electrochemical Tests. Electrochemical measurements were carried out in a conventional three-electrode $500 \mathrm{~mL}$ cylindrical Pyrex glass cell. The cell consisted of a graphite counter electrode and a silver/silver chloride, $3 \mathrm{M} \mathrm{KCl}$, reference electrode, and the working electrode in different corrosive electrolytes. Working electrodes were prepared by attaching an insulated copper wire to one face of the sample using an aluminum conducting tape, followed by cold mounting in a resin. Corrosion behaviour of the samples was investigated in $1 \mathrm{M}$ sodium chloride prepared from analytical grade sodium chloride and double distilled water. Synthetic mine water was prepared from a mixed solution of the chemicals indicated in Table 2. The final $\mathrm{pH}$ of the solution (made from neutral salts) was 7.0. Electrochemical measurements were carried out at room temperature $\left(25 \pm 1^{\circ} \mathrm{C}\right)$ with an Autolab potentiostat (PGSTAT20 computer controlled) using the General Purpose Electrochemical Software (GPES) version 4.9. Electrochemical measurements were conducted using open circuit potential (OCP) measurements, potentiodynamic polarizations, and chronoamperometric determinations. All runs were done in duplicate and showed good repeatability. Average values of electrochemical parameters calculated from the software are quoted.

For open circuit potential (OCP) measurements the cell was left for a suitable time (about 2 hours) to stabilize after the immersion of the samples in the electrolytes, before potentiodynamic polarization measurements were done. Polarization curves were obtained at varying applied voltages and at constant scan rate of $0.2 \mathrm{mV} / \mathrm{s}$ from $-250 \mathrm{mV}$ versus the open circuit potential to $1200 \mathrm{mV}$ versus the reference electrode. The corrosion potential $\left(E_{\text {corr }}\right)$ and various other characteristic electrochemical parameters, as well as the calculated corrosion rates, were obtained by using General Purpose Electrochemical Software (GPES). Chronoamperometry was used to investigate diffusion limitations in the pseudopassive/passive region, at a potential of $700 \mathrm{mV}$ versus the reference electrode potential. The potential used for chronoamperometric runs

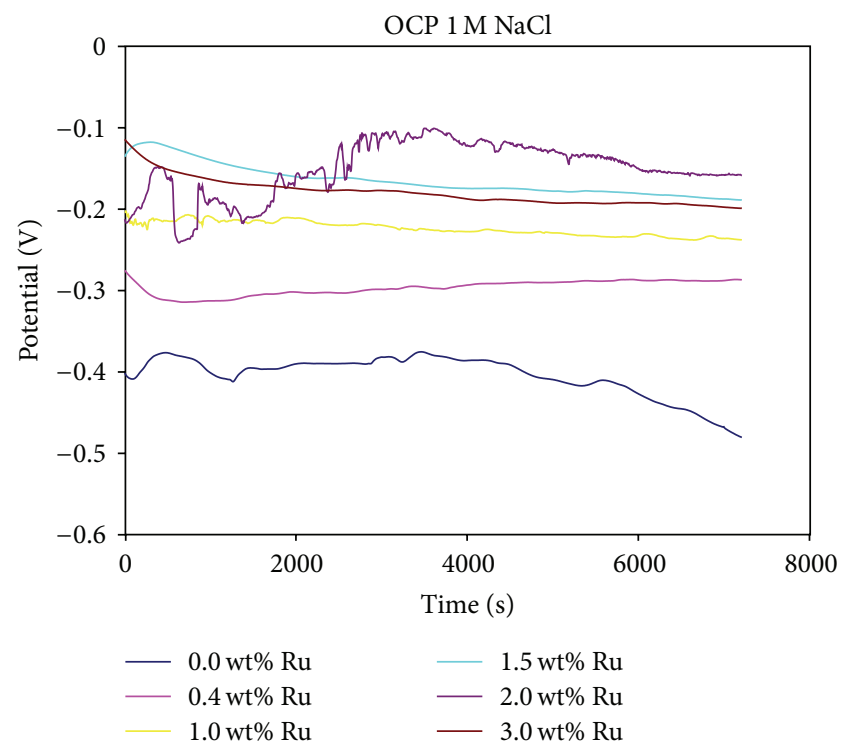

FIGURE 1: Open circuit potential results of the samples exposed to $1 \mathrm{M} \mathrm{NaCl}$.

was obtained from the pseudopassive/passive range of each specimen after conducting potentiodynamic scans.

\section{Results and Discussion}

\subsection{Sodium Chloride (1 M NaCl) Electrolyte}

3.1.1. Open Circuit Potential (OCP). The variations in the open circuit potential $\left(E_{\mathrm{oc}}\right)$ values of the samples measured for two hours in $1 \mathrm{M}$ sodium chloride are shown in Figure 1. It was observed that the open circuit potential values of the samples were unstable and showed random fluctuations in their curves. The alloy containing $3.0 \mathrm{wt} \% \mathrm{Ru}$ content had the highest (more noble) starting potential when compared to the other alloys containing lower ruthenium contents. However, as the time progressed, the potential dropped and this alloy stabilized at a slightly lower potential compared to the alloys containing $1.5 \mathrm{wt} \% \mathrm{Ru}$ and $2.0 \mathrm{wt} \% \mathrm{Ru}$. It is not clear why the alloy with $3 \% \mathrm{Ru}$ has a slightly lower final potential than the one with $1.5 \%$ and $2.0 \%$, but the variation is small and within the experimental variation often observed.

3.1.2. Potentiodynamic Polarization Measurements. Figure 2 represents electrochemical curves for the WC-Co-Ru alloys in a neutral environment of $1 \mathrm{M}$ sodium chloride, while Table 3 gives a summary of the electrochemical parameters of the WC-Co-Ru alloys exposed in this medium. The alloys all displayed active to passive transition behavior, albeit with small passive regions, which is in contrast with expected responses reported by other researchers. However, a similar response was observed when these same alloys with $\mathrm{Ru}$ were exposed to sulphuric acid [25]. Generally, the corrosion current density decreased as the ruthenium content of the various alloys increased. The alloy with $3.0 \mathrm{wt} \% \mathrm{Ru}$ showed the lowest critical and passive current density $\left(i_{\text {crit }}\right.$ and $\left.i_{\text {pass }}\right)$ 
TABLE 3: Electrochemical parameters for the investigated alloys in $1 \mathrm{M}$ sodium chloride.

\begin{tabular}{lccccccc}
\hline Sample (wt\% Ru) & $\begin{array}{c}E_{\text {corr }} \\
(\mathrm{V})\end{array}$ & $\begin{array}{c}I_{\text {corr }} \\
(\mathrm{A})\end{array}$ & $\begin{array}{c}i_{\text {crit }} \\
\left(\mathrm{A} / \mathrm{m}^{2}\right) \\
\times 10^{-6}\end{array}$ & $\begin{array}{c}i_{\text {pass }} \\
\left(\mathrm{A} / \mathrm{m}^{2}\right) \\
\times 10^{-4}\end{array}$ & $\begin{array}{c}\beta_{a} \\
(\mathrm{~V} / \mathrm{Dec})\end{array}$ & $\begin{array}{c}\beta_{c} \\
(\mathrm{~V} / \mathrm{Dec})\end{array}$ & $\begin{array}{c}\mathrm{CR} \\
(\mathrm{mm} / \mathrm{a}) \\
\times 10^{-2}\end{array}$ \\
\hline 0.0 & -0.280 & 190 & 7.89 & 3.79 & 0.016 & 0.039 \\
0.4 & -0.301 & 0.36 & 14.3 & 35.1 & 0.038 & 0.028 & 350 \\
1.0 & -0.258 & 0.90 & 35.6 & 513 & 0.039 & 0.029 & 1.62 \\
1.5 & -0.483 & 0.62 & 51.3 & 76.3 & 0.078 & 0.029 & 0.11 \\
2.0 & -0.275 & 0.16 & 0.99 & 3.36 & 0.051 & 0.021 & 0.28 \\
3.0 & -0.220 & 0.11 & 0.31 & 1.43 & 0.027 & 0.022 \\
\hline
\end{tabular}

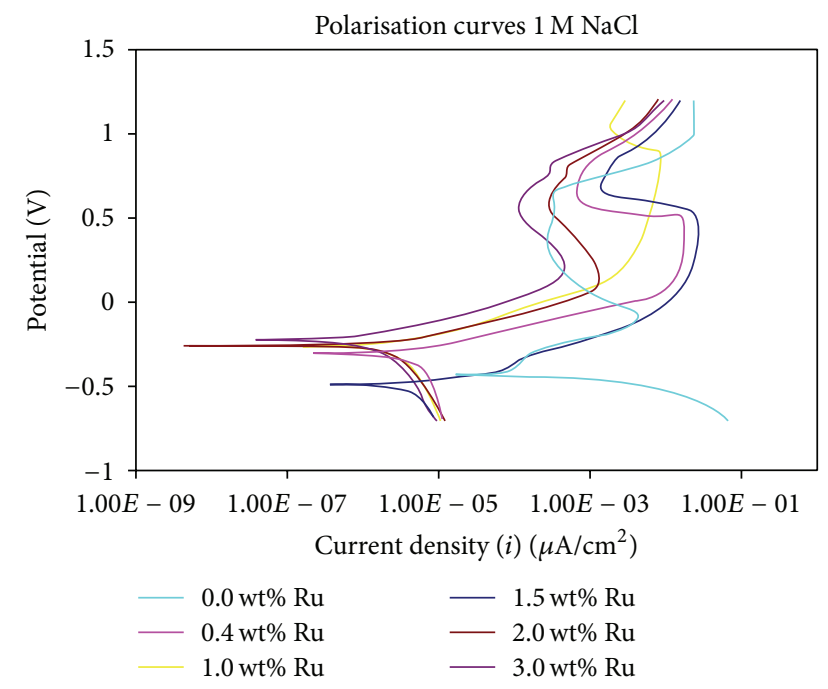

Figure 2: Comparative behavior of WC-Co in $1 \mathrm{M} \mathrm{NaCl}$ with increasing additions of Ru.

of $3.1 \times 10^{-4} \mathrm{~A} / \mathrm{cm}^{2}$ and $1.43 \times 10^{-4} \mathrm{~A} / \mathrm{cm}^{2}$, respectively, when compared to the reference alloy.

The anodic Tafel constant $\left(\beta_{a}\right)$ values showed no general trend, while the cathodic Tafel constant $\left(\beta_{c}\right)$ values decreased slightly with an increasing addition of ruthenium. The corrosion potential stays reasonably similar between the samples, except in the case of the alloy containing $1.5 \% \mathrm{Ru}$ and this can be due to a shorter wait period for the potential to stabilize before the scan was initiated. While no specific trend could be distinguished in the $i_{\text {pass }}$ values, there is a decreasing trend in the $i_{\text {crit }}$ values with increasing Ru contents in the alloys, which is indicative of an inhibition of the anodic dissolution part of the corrosion process. There is a noticeable change in corrosion rates with the addition of ruthenium. The initial decrease is quite substantial, and thereafter the corrosion rate decreased slightly as the ruthenium content increases. This decrease can be ascribed to the effect of the added Ru on both the anodic inhibition and a lowering of the cathodic reaction rate, similar to cases of stainless steels with $\mathrm{Ru}$ additions in such an environment [27].

3.1.3. Chronoamperometry Measurements. The chronoamperometric behaviour of the samples is displayed in Figure 3.

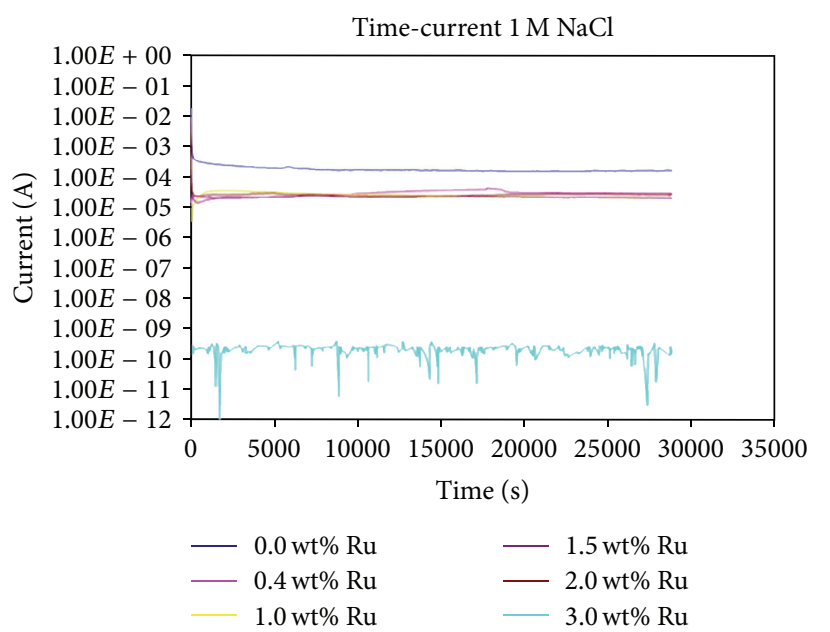

Figure 3: Current-time responses of the WC-Co-Ru samples exposed to $1 \mathrm{M} \mathrm{NaCl}$ at an applied potential of $700 \mathrm{mV}$ versus $\mathrm{Ag} / \mathrm{AgCl}$ reference electrode.

All the alloys had almost the same polarization current, except for the reference alloy, which showed a slightly higher polarization current when compared to the ruthenium containing alloys. It was also observed that the alloy containing $3.0 \mathrm{wt} \% \mathrm{Ru}$ had an anomalously low polarization current at the applied potential. It is not clear whether this was due to an error in the measurement setup and it requires further investigation. Measurements done on the alloys in $1 \mathrm{M}$ sodium chloride revealed that the increasing amount of ruthenium increased the corrosion resistance of the WC-Co alloys. The product film formed on the surface is stable with no indication of breakdown for the investigated period of 8 hours.

3.1.4. Surface Area Analyses and Topography. SEM micrographs of the WC-Co-Ru/VC alloys after corrosive attack in the sodium chloride solution indicated the presence of products/precipitates on the surface, which covered some part of the sample surface. EDS analysis showed that it consisted mostly of sodium chloride crystals. An example of the base alloy and one containing a Ru addition is shown in Figures 4(a) and 4(b). At the same time, no difference could be detected from the SEM micrographs in the microstructure 


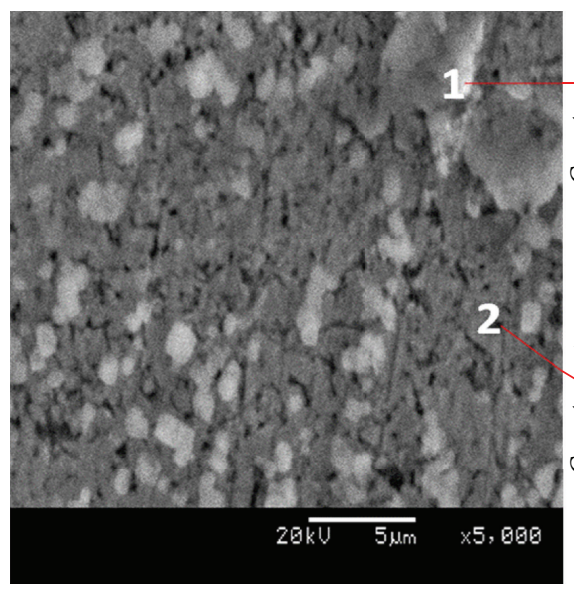

, 690

(a)
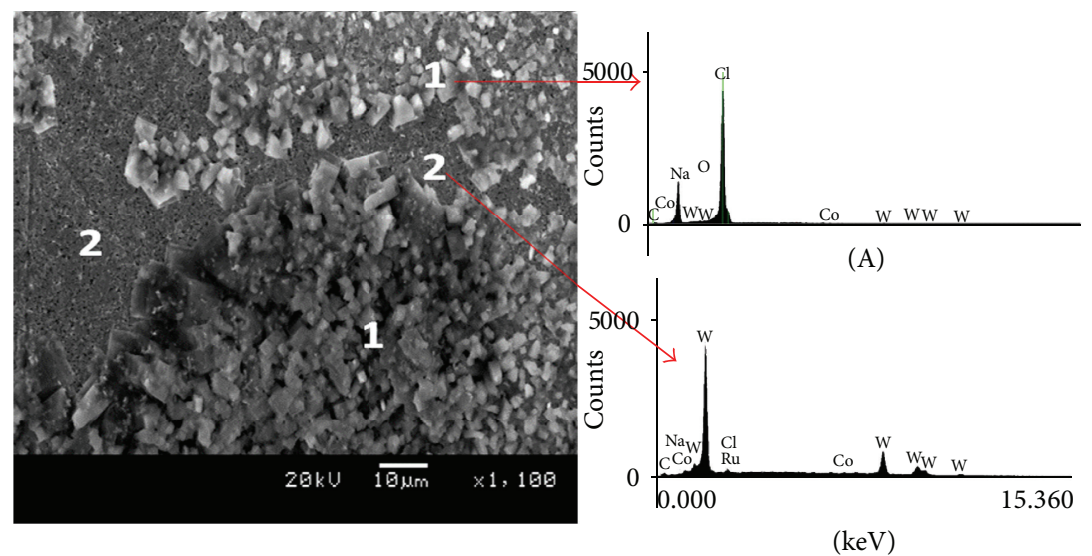

(B)

(b)

FIgURE 4: (a) The SEM micrograph of the $0 \mathrm{wt} \% \mathrm{Ru}$ containing alloy after exposure to $1 \mathrm{M} \mathrm{NaCl}$ solution with corresponding EDS spectra analyses of (A) area 1 and (B) area 2. (b) The SEM micrograph of the $0.4 \mathrm{wt} \% \mathrm{Ru}$ containing alloy after exposure to $1 \mathrm{M} \mathrm{NaCl}$ solution with corresponding EDS spectra analyses of (A) area 1 and (B) area 2.

of the alloys containing $\mathrm{Ru}$ as compared to the base alloy without it. Taking into account the method of manufacturing of these different alloys, that is, hot isostatic pressing (HIP), which results in a limited amount of porosity anyway, it is unlikely that an influence of $\mathrm{Ru}$ on the microstructure would have been so pronounced that it would be detected in any SEM measurement.

3.1.5. Raman Analysis. Raman analyses were performed on the surfaces of the corroded alloys to confirm the compounds formed on the surface during the polarisation of the alloys in the sodium chloride solution. Raman spectra of WC-Co$\mathrm{Ru}$ after exposure to $1 \mathrm{M}$ sodium chloride are all presented in Figure 5 over a range of $100-1500 \mathrm{~cm}^{-1}$. All visible shifts are summarized in Table 4.

A summary of the main shift positions observed is given in Table 4. Alloys containing $0 \% \mathrm{Ru}, 0.4 \% \mathrm{Ru}$, and $1.5 \%$ $\mathrm{Ru}$ have similar shifts with the average values of $647 \mathrm{~cm}^{-1}$,
$520 \mathrm{~cm}^{-1}, 456 \mathrm{~cm}^{-1,}$ and $223 \mathrm{~cm}^{-1}$, while the other remaining alloys in Table 4 have similar shifts with the average values of $1421 \mathrm{~cm}^{-1}, 1022 \mathrm{~cm}^{-1}, 861 \mathrm{~cm}^{-1}, 662 \mathrm{~cm}^{-1}, 406 \mathrm{~cm}^{-1}$ and $142 \mathrm{~cm}^{-1}$. The alloy containing $2.0 \% \mathrm{Ru}$ showed only three broad peaks corresponding in position with similar ones in the alloys containing $1 \% \mathrm{Ru}$ and $3 \% \mathrm{Ru}$. The absence of further corresponding peaks in the spectrum of the $2 \% \mathrm{Ru}$ alloy's surface could be due to different sample handling conditions between the electrochemical measurements and the recording of the Raman data, or a difference in the measuring conditions and parameters employed during the scan recording when compared with the rest of the investigated alloys. Some of the shifts were in the same range as those obtained by Arai et al. [28] and Shiyanovskaya et al. [29]. Arai et al. [28] reported that the shift around $800 \mathrm{~cm}^{-1}$ is usually attributed to $\mathrm{W}-\mathrm{O}$ stretching modes, while the shifts around $300 \mathrm{~cm}^{-1}$ and $150 \mathrm{~cm}^{-1}$ are attributable to $\mathrm{W}-\mathrm{O}$ deformation and $\mathrm{O}-\mathrm{O}$ deformation modes, respectively. The 
TABLE 4: Peak positions found on the surface of WC-Co-Ru/VC alloys after exposure in $1 \mathrm{M}$ sodium chloride solution.

\begin{tabular}{|c|c|c|c|c|c|c|c|}
\hline \multirow{2}{*}{ Sample (wt\% Ru) } & \multicolumn{7}{|c|}{ Raman peaks of samples after exposure to sodium chloride } \\
\hline & Peak 1 & Peak 2 & Peak 3 & Peak 4 & Peak 5 & Peak 6 & Peak 7 \\
\hline 0.0 & & & & 687 & 516 & 456 & 261 \\
\hline 0.4 & & & & 628 & 519 & 456 & 128 \\
\hline 1.5 & & & & 627 & 525 & 456 & 281 \\
\hline 1.0 & 1451 & 1041 & 845 & 663 & & 406 & 123 \\
\hline 2.0 & 1362 & & 886 & & & & 184 \\
\hline 3.0 & 1449 & 1002 & 853 & 661 & & 406 & 118 \\
\hline
\end{tabular}

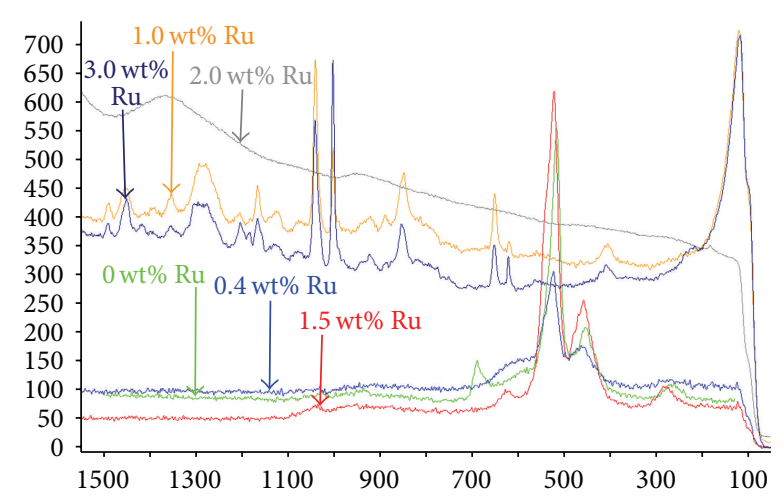

Figure 5: Raman spectra of all the alloys after exposure to $1 \mathrm{M}$ sodium chloride solution.

authors concluded that this indicated the presence of $\mathrm{WO}_{3}$. Shiyanovskaya and coworkers [29] detected $\mathrm{WO}_{3} \cdot 1 / 3 \mathrm{H}_{2} \mathrm{O}$. In addition, some of the cobalt has been oxidised by oxygen to form cobalt oxides in the form of $\mathrm{CoO}$ and $\mathrm{Co}_{3} \mathrm{O}_{4}$. The various oxides detected formed during the passivation stages in the potentiodynamic scan regimes of the different alloys and contributed to the decreased corrosion rates observed and recorded in Table 3. It seemed that in some cases only one type of metal oxide formed during the surface passivation stage, for example, only the Co oxides (peak positions 4-6), while at other times the presence of both tungsten oxides and cobalt oxides was detected. This could be due to the differences between the samples in sample handling and storage, as well as periods before analyses after completion of the potentiodynamic scans. Instrument conditions and optimisation could also have played a role why both types of metal oxides were not consistently identified on all the samples.

\subsection{Synthetic Mine Water}

3.2.1. Open Circuit Potential (OCP). The variation of the open circuit corrosion potentials (OCPs) of the WC-Co$\mathrm{Ru} / \mathrm{VC}$ alloys for the period of two hours after exposure to synthetic mine water is shown in Figure 6. The reference alloy containing $0 \mathrm{wt} \% \mathrm{Ru}$ revealed the lowest OCP values when compared to the other alloys. It was observed that as the amount of ruthenium increased, the potential values slightly increased. However, there was a drastic increase in

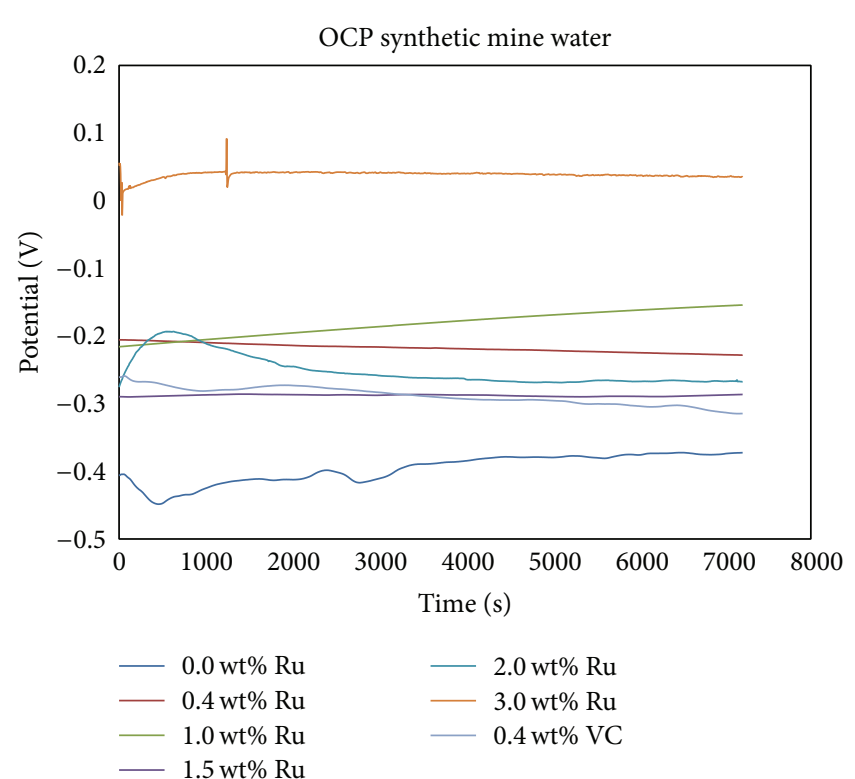

FIGURE 6: Open circuit potential results of the samples exposure to synthetic mine water.

potential values of the alloy containing $3.0 \mathrm{wt} \% \mathrm{Ru}$ stabilizing at the positive potential of $0.03 \mathrm{~V}$. The potential values at 7200 s illustrate that the alloys with increasing amounts of the ruthenium are nobler than the one without ruthenium and the one containing VC.

3.2.2. Potentiodynamic Polarization Measurements. Figure 7 shows the polarization curves obtained in synthetic mine water solution. Contrary to the case in sodium chloride media, the polarization curves display the characteristic pseudopassivation behavior one typically observes in acidic media, in agreement with the observations made by Human and Exner [8], as well as Machio [30]. The alloy containing $0.4 \mathrm{wt} \% \mathrm{VC}$ showed better corrosion resistance than the alloy containing $0 \mathrm{wt} \% \mathrm{Ru}$. All the alloys containing ruthenium revealed better corrosion resistance than the alloy containing $0.4 \mathrm{wt} \% \mathrm{VC}$, with the alloys containing $2.0 \mathrm{wt} \%$ and $3.0 \mathrm{wt} \%$ $\mathrm{Ru}$ performing the best of all. The alloys containing $2.0 \mathrm{wt} \%$ and $3.0 \mathrm{wt} \% \mathrm{Ru}$ showed a drastic decrease in corrosion rate compared to the rest. 
TABLE 5: Electrochemical parameters for the samples in synthetic mine water.

\begin{tabular}{lccccc}
\hline Sample $(\mathrm{wt} \% \mathrm{Ru})$ & $\begin{array}{c}E_{\text {corr }} \\
(\mathrm{V})\end{array}$ & $\begin{array}{c}I_{\text {corr }} \\
(\mathrm{A}) \\
\times 10^{-6}\end{array}$ & $\begin{array}{c}\beta_{a} \\
(\mathrm{~V} / \mathrm{Dec})\end{array}$ & $\begin{array}{c}\beta_{c} \\
(\mathrm{~V} / \mathrm{Dec}) \\
(\mathrm{mm} / \mathrm{a}) \\
\times 10^{-2}\end{array}$ \\
\hline 0.0 & -0.429 & 4.33 & 0.037 & 0.075 & 7.79 \\
0.4 & -0.277 & 1.04 & 0.116 & 0.058 & 0.034 \\
1.0 & -0.230 & 0.79 & 0.027 & 0.026 & 1.97 \\
1.5 & -0.319 & 0.90 & 0.014 & 0.020 & 0.102 \\
2.0 & -0.135 & 0.06 & 0.080 & 0.018 & 0.004 \\
3.0 & -0.020 & 0.0002 & 0.040 & 0.029 & 2.22 \\
$0.4 \mathrm{VC}$ & -0.361 & 1.23 & 0.071 & & 0.02 \\
\hline
\end{tabular}

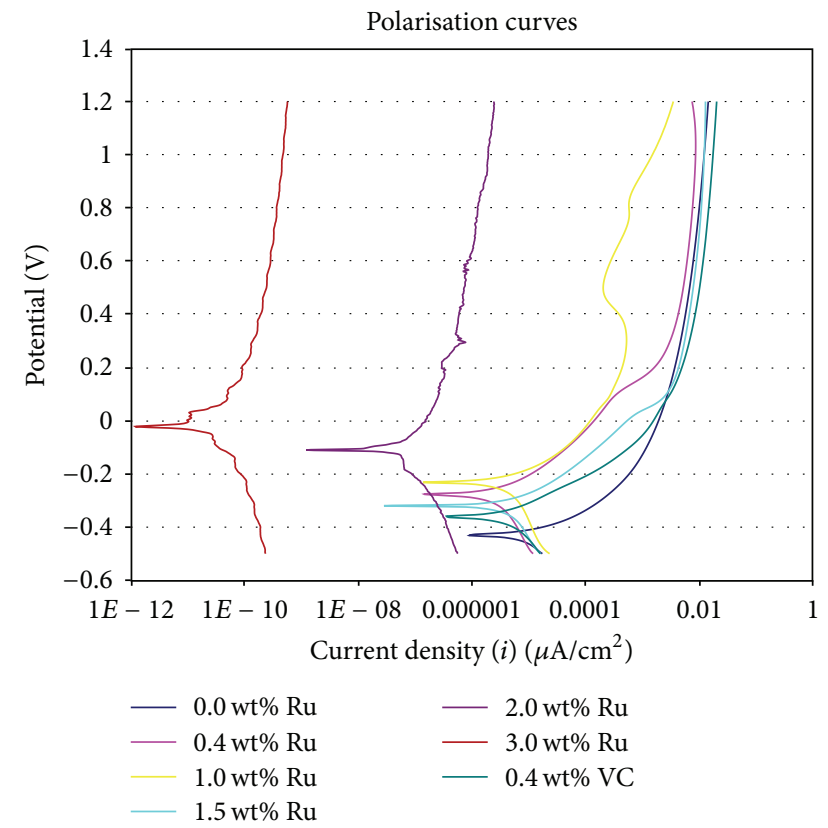

FIGURE 7: Comparative corrosion behavior of WC-Co in synthetic mine water with increasing additions of Ru and VC.

The typical electrochemical parameters derived from these scans are summarized in Table 5.

From these values, it can be seen that the corrosion potential generally increased as the amount of ruthenium increased. It was also noted that the corrosion current density decreased with increasing ruthenium contents in the synthetic mine water solution. While the anodic Tafel constants varied in no particular trend or pattern, there is a progressive decrease in the value of the cathodic Tafel constants with an increasing amount of $\mathrm{Ru}$ added to the base alloy. This is an indication that the $\mathrm{Ru}$ displays the same effect on the cathodic reaction as was observed in a previous investigation [25] in sulphuric acid with WC-Co alloys containing Ru and also as has been reported to be the case when stainless steels containing PGM additions are exposed to corrosive nonoxidising acid solutions [31]. Compared to the base alloy (without $\mathrm{Ru}$ ), the corrosion rate and the corrosion current density for alloy containing $2.0 \mathrm{wt} \% \mathrm{Ru}$ were reduced by one and two orders of magnitude, respectively, while for alloy containing $3.0 \mathrm{wt} \% \mathrm{Ru}$ both the corrosion rate and the corrosion current density were several orders of magnitude lower (three and four, resp.). The alloy containing $0 \% \mathrm{Ru}$ showed the least corrosion resistance while the alloy containing 3.0\% Ru displayed the best resistance to corrosion. The alloy with $0.4 \%$ $\mathrm{Ru}$ had a similar, but slightly lower, corrosion rate than the one with $0.4 \% \mathrm{VC}$, while all the alloys with higher Ru contents outperformed the ones with the $0.4 \% \mathrm{VC}$ addition.

It is very obvious that the mine water solution is the less corrosive and aggressive medium of the two media evaluated. The alloys in the sodium chloride medium displayed active to passive transition behavior upon polarization, in contrast with those in the synthetic mine water, which displayed pseudopassivation behavior. Corrosion rates in general are higher in the sodium chloride for the alloys investigated, particularly the base alloy, and the two with the highest amounts of $\mathrm{Ru}$, that is, $2.0 \mathrm{wt} \%$ and $3.0 \mathrm{wt} \% \mathrm{Ru}$. This can be ascribed to the at least 10 times lower chloride concentration in the synthetic mine water solution compared to the sodium chloride solution. In both media the difference in corrosion rates between the alloy with $2.0 \mathrm{wt} \% \mathrm{Ru}$ and the alloy with $3.0 \mathrm{wt} \% \mathrm{Ru}$ does not warrant the additional expense of a further $1 \mathrm{wt} \% \mathrm{Ru}$ addition to the one containing $2 \mathrm{wt} \% \mathrm{Ru}$. Because $\mathrm{Ru}$ is the most expensive component in the alloy makeup, one has to try and limit such an addition to the lowest possible amount to gain the maximum benefit in terms of enhancement of the corrosion resistance of the base alloy. From this point of view the alloy containing $2.0 \mathrm{wt} \% \mathrm{Ru}$, which lowers the corrosion rate by two to three orders of magnitude compared to the base alloy, offers the best choice. The corrosion rates observed in this investigation are lower than in acid solutions of similar strength and concentration $[25,32]$.

3.2.3. Chronoamperometry Measurements. The chronoamperometric behaviour of the WC-Co-Ru/VC alloys in synthetic mine water solution shown in Figure 8 indicates that current decreased as ruthenium addition increased. The alloys exhibited similar behavior except for alloys containing $0 \mathrm{wt} \%, 0.4 \mathrm{wt} \%$, and $1.0 \mathrm{wt} \% \mathrm{Ru}$ which showed a steady decrease in current as the time progressed up till the 7000th second after which it started to stabilize. This confirmed the pseudopassivation of the alloys in synthetic mine water 
TABLE 6: Raman peak positions $\left(\mathrm{cm}^{-1}\right)$ found on the surface of WC-Co-Ru/VC alloys after exposure in synthetic mine water solution.

\begin{tabular}{|c|c|c|c|c|c|c|}
\hline \multirow{2}{*}{ Sample (wt\% Ru) } & \multicolumn{6}{|c|}{ Raman peaks of samples after exposure to synthetic mine water } \\
\hline & Peak 1 & Peak 2 & Peak 3 & Peak 4 & Peak 5 & Peak 6 \\
\hline 0.0 & 1582 & 1232 & - & 598 & 527 & 128 \\
\hline 0.4 & 1596 & 1337 & - & 581 & 527 & 139 \\
\hline 1.0 & 1613 & 1374 & 857 & 619 & 520 & 122 \\
\hline 1.5 & 1586 & 1436 & 867 & 598 & 530 & 152 \\
\hline 2.0 & 1572 & - & - & 656 & 510 & 186 \\
\hline 3.0 & 1596 & 1014 & 898 & 625 & 525 & 144 \\
\hline $0.4 \mathrm{VC}$ & 1569 & 1187 & - & 666 & 523 & 190 \\
\hline Average & $1588 \pm 25$ & $1263 \pm 173$ & $874 \pm 24$ & $620 \pm 46$ & $523 \pm 13$ & $152 \pm 38$ \\
\hline
\end{tabular}

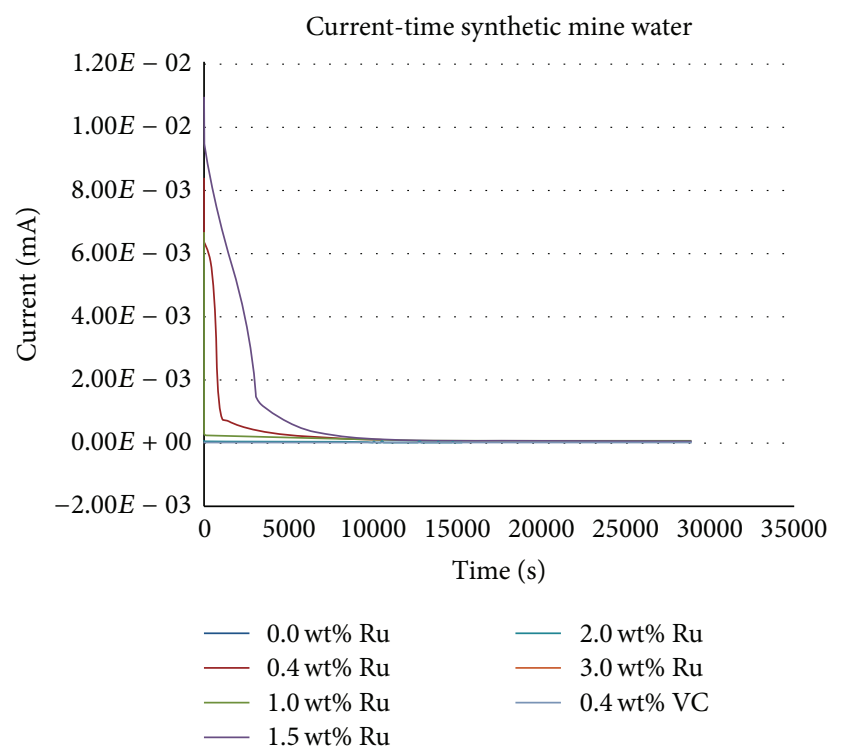

Figure 8: Current-time results of the samples exposure to synthetic mine water at an applied potential of $700 \mathrm{mV}$ versus $\mathrm{Ag} / \mathrm{AgCl}$ reference electrode.

solution observed in the polarization curves. The passive films formed on the surfaces seem to be fairly stable, as no indication of the film breakdown was observed. The alloy containing $0.4 \% \mathrm{VC}$ displayed a similar curve to that of the other $\mathrm{Ru}$ containing alloys with $>1.0 \mathrm{wt} \% \mathrm{Ru}$, that is, stable passivity.

It was noted that as the amount of ruthenium increased, the open circuit potential values $\left(E_{\mathrm{oc}}\right)$ shifted to more noble values. The increase in open circuit potential observed could result from the formation of passive films on the surfaces of the alloys. Figure 8 revealed that the film that formed on the surface did not undergo any breakdown after exposure to synthetic mine water for 8 hours.

Recently Olubambi et al. [33] reported that an increase in passivity with increasing ruthenium contents might be an indication that ruthenium increases the passivation region, possibly through the replacement and substitution of cobalt binder after its selective dissolution. It is possible that after cobalt is lost from the alloy, ruthenium could diffuse and accumulate on the defect sites within the surface of the alloys, thereby inducing passivity. Tjong et al. [34] observed that the accumulation of the ruthenium atoms on the surface of the alloy could promote the efficiency for hydrogen evolution, thereby moving the corrosion potential towards the noble direction, and resulting in spontaneous passivation when the surface concentration of ruthenium reaches a critical value. This argument correlates well with the lowered decrease in the cathodic Tafel constants with an increased ruthenium content in the alloys that was observed in this investigation, as well as the shift of the open circuit corrosion potential to more noble values. Furthermore, the ruthenium adatoms on the surface of the corroded alloys are also more corrosion resistant than the cobalt atoms, and this contributes to the increased corrosion resistance against corrosive media. This is corroborated by the observed decrease in $i_{\text {crit }}$ recorded during potentiodynamic scans.

3.2.4. Scanning Electron Microscope. The surfaces of the alloys examined after the polarization tests in the electron microscope showed that all samples experienced corrosion during the tests. It was observed that the surfaces were completely covered by corrosion product. EDX analysis revealed that this corrosion product constitutes of high amounts of oxygen, sulphur, and chloride. These results are consistent with those reported previously on similar type WC-Co alloys without the Ru additions [30]. Selected micrographs of some of the microstructures, along with the chemical composition of the various elements observed on the surfaces of the alloys after exposure to synthetic mine water, are given in Figures 9(a)-9(c). No pitting corrosion was observed in either of the two aggressive chloride containing media.

3.2.5. Raman Spectrometry. Raman spectra of the WC-Co$\mathrm{Ru} / \mathrm{VC}$ alloys after exposure to synthetic mine water is illustrated in Figure 10. Raman identifiable shifts of samples are summarised in tables for each alloy exposed to synthetic mine water. The most prominent shifts of all the alloys are at average wavenumbers of $523 \pm 13 \mathrm{~cm}^{-1}$ and the lower shift at $152 \pm 38 \mathrm{~cm}^{-1}$ (Table 6).

Raman spectroscopic analyses indicated the presence of tungsten oxide and hydrated tungsten oxide compounds and $\mathrm{CoO}$ and $\mathrm{Co}_{3} \mathrm{O}_{4}$ which formed in the corrosion process, in 


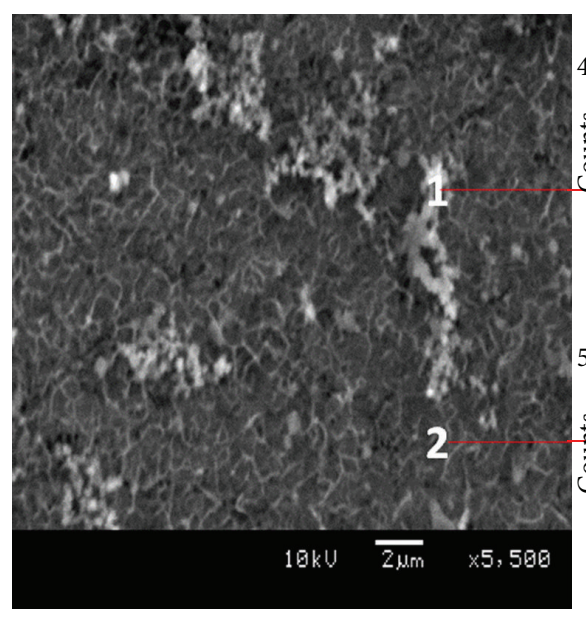

(a)
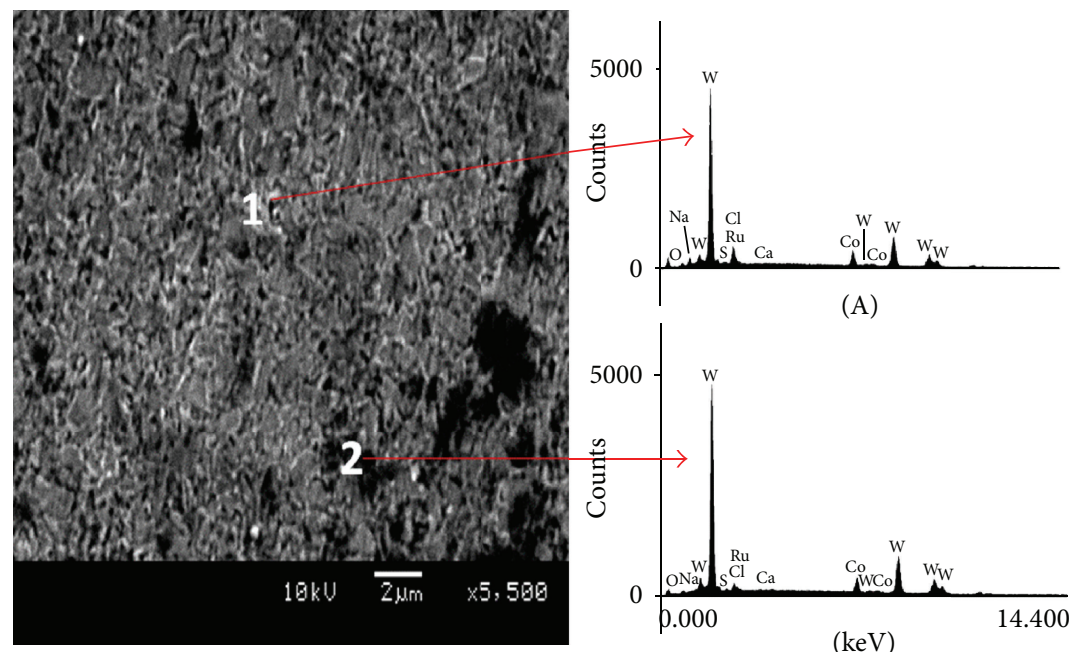

(B)

(b)
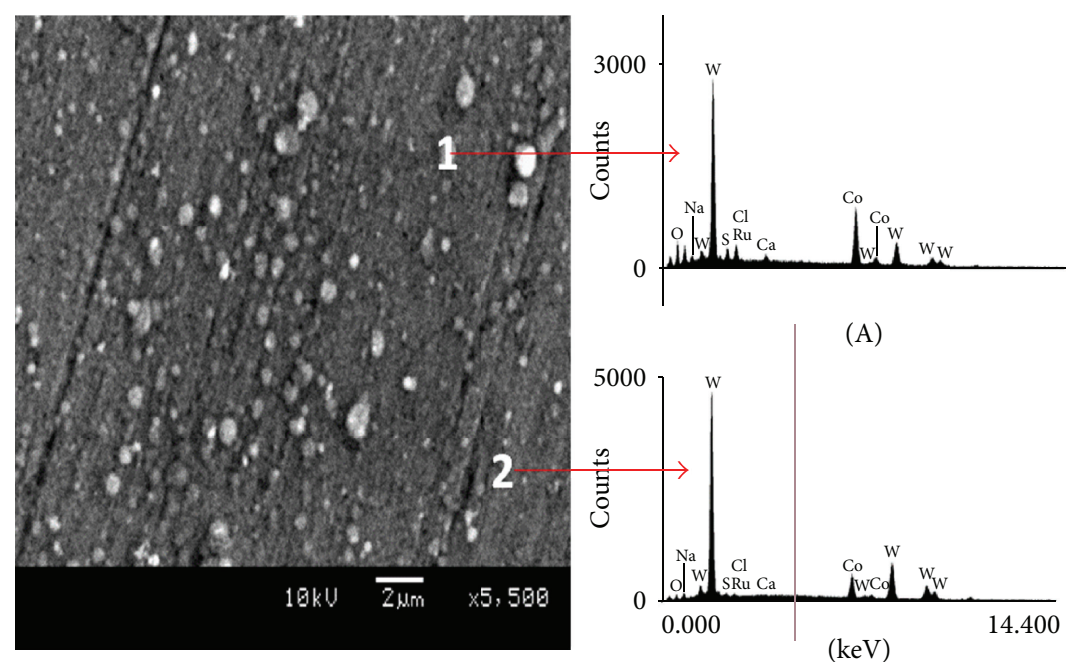

(B)

(c)

FIGURE 9: (a) SEM micrograph of the WC-10\% Co alloy after exposure to synthetic mine water solution with corresponding EDX spectra analyses of (A) area 1 and (B) area 2. (b) SEM micrograph of the $3.0 \mathrm{wt} \% \mathrm{Ru}$ containing alloy after exposure to synthetic mine water solution with corresponding EDX spectra analyses of (A) area 1 and (B) area 2. (c) SEM micrograph of the 0.4 wt\% VC containing alloy after exposure to synthetic mine water solution with corresponding EDX spectra analyses of (A) area 1 and (B) area 2. 


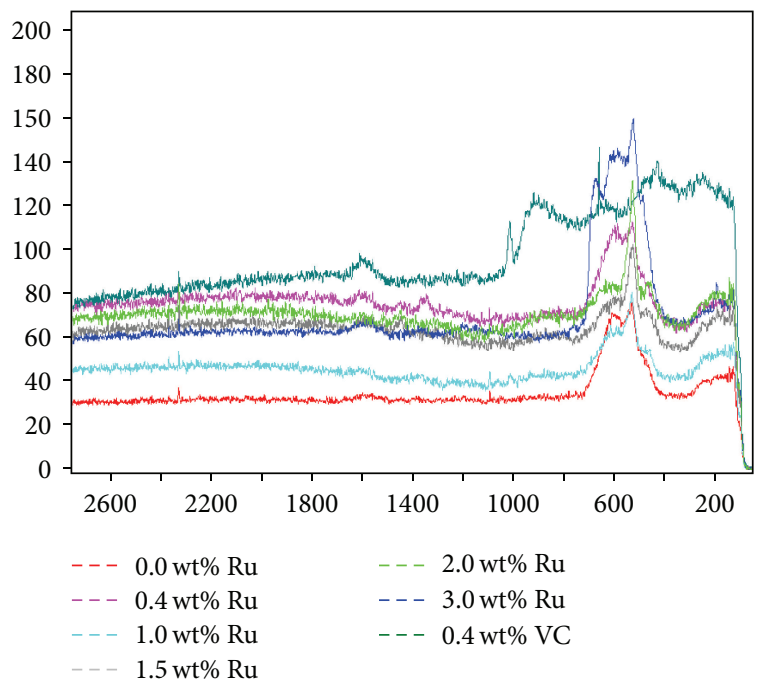

Figure 10: Raman spectra of selected alloys after exposure to synthetic mine water.

accordance with results and spectra reported by several other investigators $[32,35,36]$. One can thus conclude that the pseudopassive behavior observed is due to the formation of various cobalt and tungsten oxide films on the surface of the alloys during exposure to the synthetic mine water solution.

\section{Conclusions}

The following conclusions can be made from this investigation.

(1) All the alloys evaluated experienced more corrosion in the sodium chloride alone than to the synthetic mine water solution, which consists of a mixture of chloride and sulphate salts, albeit at lower amounts.

(2) An increasing amount of $\mathrm{Ru}$ improves the corrosion resistance of all the alloys, although the effect is not as dramatic as that observed with stainless steels containing $\mathrm{Ru}$ that were placed in corrosive media. Nevertheless, the decrease in corrosion rate in sodium chloride and synthetic mine water is spectacular for the two alloys containing the highest amounts of $\mathrm{Ru}(2$ and $3 \mathrm{wt} \%$, resp.) when compared to the other alloys and especially the base one without any Ru.

(3) The alloy containing VC has a lower corrosion resistance in synthetic mine water than the one with a similar amount of Ru.

(4) The corrosion potential is displaced towards more electropositive values for all the alloys containing $\mathrm{Ru}$ compared to the base alloy. The displacement is the most dramatic in the synthetic mine water solution and the magnitude generally increases with an increasing amount of Ru.
(5) In both corrosive media there is evidence that the presence of the Ru decreased the cathodic Tafel constant in a systematic way and has a retarding influence on the cathodic part of the corrosion reaction.

(6) In the sodium chloride solution, the various alloys displayed typical active to passive transition behaviour when polarised, and it could be deduced that $\mathrm{Ru}$ also had an effect on the anodic dissolution part of the corrosion reaction. The beneficial effect of the $\mathrm{Ru}$ in improving corrosion resistance in this medium was clear from the reduction in the critical current density and corrosion current density with an increased amount of $\mathrm{Ru}$ in the various alloys.

(7) SEM micrographs indicated that crystalline corrosion products formed on all the alloys exposed in the two chloride media. In the case of the sodium chloride solution, these were sodium chloride crystals, while the salt-like crystals detected on the various alloy surfaces exposed in synthetic mine water were rich in sulphur, oxygen, and chlorine, thus implying the crystallisation of chloride and sulphate type salts on the alloy surfaces.

(8) Raman spectroscopic analyses of the corroded surfaces indicated the presence of tungsten oxide and hydrated tungsten oxide compounds which formed during the corrosion process. Evidence was also found that cobalt oxides in the form of $\mathrm{CoO}$ and $\mathrm{Co}_{3} \mathrm{O}_{4}$ formed in the corrosion process.

\section{Conflict of Interests}

The authors declare that there is no conflict of interests regarding the publication of this paper.

\section{Acknowledgments}

The authors gratefully acknowledge the financial support of the DST/NRF Centre of Excellence in Strong Materials for financial support and the School of Chemical \& Metallurgical Engineering at the University of the Witwatersrand for laboratory facilities.

\section{References}

[1] B. Schnyder, C. Stössel-Sittig, R. Kötz et al., "Investigation of the electrochemical behaviour of WC-Co hardmetal with electrochemical and surface analytical methods," Surface Science, vol. 566-568, no. 1-3, pp. 1240-1245, 2004.

[2] E. J. Wentzel and C. Allen, "The erosion-corrosion resistance of tungsten-carbide hard metals," International Journal of Refractory Metals and Hard Materials, vol. 15, no. 1-3, pp. 81-87, 1997.

[3] A. M. Human and H. E. Exner, "Electrochemical behaviour of tungsten-carbide hardmetals," Materials Science and Engineering A, vol. 209, no. 1-2, pp. 180-191, 1996.

[4] S. Hochstrasser(-Kurz), Y. Mueller, C. Latkoczy, S. Virtanen, and P. Schmutz, "Analytical characterization of the corrosion 
mechanisms of WC-Co by electrochemical methods and inductively coupled plasma mass spectroscopy," Corrosion Science, vol. 49, no. 4, pp. 2002-2020, 2007.

[5] V. A. Pugsley and H. G. Sockel, "Corrosion fatigue of cemented carbide cutting tool materials," Materials Science and Engineering A, vol. 366, no. 1, pp. 87-95, 2004.

[6] H. Scholl, B. Z. E. Hofman, and A. Rauscher, "Anodic polarization of cemented carbides of the type [(WC,M): $\mathrm{M}=\mathrm{Fe}, \mathrm{Ni}$ or Co] in sulphuric acid solution," Electrochimica Acta, vol. 37, no. 3, pp. 447-452, 1992.

[7] W. J. Tomlinson and N. J. Ayerst, "Anodic polarization and corrosion of WC-Co hardmetals containing small amounts of Cr3C2 and/or VC," Journal of Materials Science, vol. 24, no. 7, pp. 2348-2352, 1989.

[8] A. M. Human and H. E. Exner, "The relationship between electrochemical behaviour and in-service corrosion of WC based cemented carbides," International Journal of Refractory Metals and Hard Materials, vol. 15, no. 1-3, pp. 65-71, 1997.

[9] S. Sutthiruangwong and G. Mori, "Corrosion properties of Co-based cemented carbides in acidic solutions," International Journal of Refractory Metals and Hard Materials, vol. 21, no. 3-4, pp. 135-145, 2003.

[10] W. J. Tomlinson and C. R. Linzell, "Anodic polarization and corrosion of cemented carbides with cobalt and nickel binders," Journal of Materials Science, vol. 23, no. 3, pp. 914-918, 1988.

[11] A. F. Lisovsky, N. V. Tkachenko, and V. Kebko, "Structure of a binding phase in re-alloyed WC-Co cemented carbides ," International Journal of Refractory Metals and Hard Materials, vol. 10, no. 1, pp. 33-36, 1991.

[12] C. Ringas, F. P. A. Robinson, S. B. Luyckx, and J. P. F. Sellschop, "Corrosion behaviour of ion implanted WC-Co and WC$\mathrm{Ni}$ alloys in acid and chloride containing media," Surface Engineering, vol. 6, no. 3, pp. 194-198, 1990.

[13] S. Sutthiruangwong, G. Mori, and R. Kosters, "Passivity and pseudopassivity of cemented carbides," International Journal of Refractory Metals and Hard Materials, vol. 23, no. 2, pp. 129-136, 2005.

[14] C. Bonjour, "Effects of ruthenium additions on the properties and machining behaviour of WC-Co hard metals," Powder Metallurgy Tool Material, p. 529, 2004.

[15] T. L. Shing, S. Luyckx, and I. T. Northrop, "The effect of ruthenium additions on the hardness, toughness and grain size of WC-Co," International Journal of Refractory Metals and Hard Materials, vol. 19, no. 1, pp. 41-44, 2001.

[16] T. L. Shing, R. H. Eric, and S. Luyckx, "Ruthenium as an etaphase inhibitor in WC-Co," in Proceedings of the European Conference on Hard Materials and Diamond Tooling, pp. 9299, European Powder Metallurgy Assocbellstone, Lausanne, Switzerland, 2002.

[17] C. Bonjour and A. Actis-Data, "Effects of ruthenium additions on the properties of WC-Co ultra micrograins," Powder Metallurgy Tool Material, p. 543, 2004.

[18] J. H. Potgieter, W. Skinner, and A. M. Heyns, "The nature of the passive film on cathodically modified stainless steels," Journal of Applied Electrochemistry, vol. 23, no. 1, pp. 11-18, 1993.

[19] J. H. Potgieter, "Alloys cathodically modified with noble metals," Journal of Applied Electrochemistry, vol. 21, no. 6, pp. 471-482, 1991.

[20] J. H. Potgieter, "The effect of small ruthenium additions on the corrosion behaviour of various duplex stainless steels in sulphuric acid," South African Journal of Chemistry, vol. 46, p. $58,1993$.
[21] J. H. Potgieter, A. M. Heyns, and W. Skinner, "Cathodic modification as a means of improving the corrosion resistance of alloys," Journal of Applied Electrochemistry, vol. 20, no. 5, pp. 711-715, 1990.

[22] I. M. Wolff, "New applications for ruthenium," South African Journal of Science, vol. 95, p. 539, 1999.

[23] I. M. Wolff, L. E. Iorio, T. Rumpf, P. V. T. Scheers, and J. H. Potgieter, "Oxidation and corrosion behaviour of Fe-Cr and Fe$\mathrm{Cr}-\mathrm{Al}$ alloys with minor alloying additions," Materials Science and Engineering A, vol. 241, no. 1-2, pp. 264-276, 1998.

[24] G. Myburg, K. Varga, W. O. Barnard et al., "Surface composition of Ru containing duplex stainless steel after passivation in nonoxidizing media," Applied Surface Science, vol. 136, no. 1-2, pp. 29-35, 1998.

[25] J. H. Potgieter, N. Thanjekwayo, P. Olubambi, N. Maledi, and S. S. Potgieter-Vermaak, "Influence of $\mathrm{Ru}$ additions on the corrosion behaviour of WC-Co cemented carbide alloys in sulphuric acid," International Journal of Refractory Metals and Hard Materials, vol. 29, no. 4, pp. 478-487, 2011.

[26] R. Polini, "Chemically vapour deposited diamond coatings on cemented tungsten carbides: substrate pretreatments, adhesion and cutting performance," Thin Solid Films, vol. 515, no. 1, pp. $4-13,2006$.

[27] E. M. Sherif, J. H. Potgieter, J. D. Comins, L. Bleksly, P. A. Olubambia, and C. N. Machio, "The beneficial effect of ruthenium additions on the passivation of duplex stainless steel corrosion in sodium chloride solutions," Corrosion Science, vol. 51, no. 6, pp. 1364-1371, 2009.

[28] M. Arai, S. Hayashi, K. Yamamoto, and S. S. Kim, "Raman studies of phase transitions in gas-evaporated $\mathrm{WO}_{3}$ microcrystals," Solid State Communications, vol. 75, no. 7, pp. 613-616, 1990.

[29] I. Shiyanovskaya, H. Ratajczak, J. Baran, and M. Marchewka, "Fourier transform raman study of electrochromic crystalline hydrate films w031/3(H2O)," Journal of Molecular Structure, vol. 348, pp. 99-102, 1995.

[30] C. N. Machio, Preparation, characterisation and testing of WC-VC-CO HP/HV of thermal spray coatings [Ph.D. thesis], University of the Witwatersrand, Johannesburg, South Africa, 2005.

[31] J. H. Potgieter, "Corrosion of passive alloys: the effect of noble metal additions," in Shreirs Corrosion, J. ARichardson, R. ACottis, J. D. Scantlebury et al., Eds., vol. 3, p. 2224, Elsevier, 2010.

[32] D. S. Konadu, J. V. D. Merwe, J. H. Potgieter, S. PotgieterVermaak, and C. N. Machio, "The corrosion behaviour of WCVC-Co hardmetals in acidic media," Corrosion Science, vol. 52, no. 9, pp. 3118-3125, 2010.

[33] P. A. Olubambi, J. H. Potgieter, and L. Cornish, "Corrosion behaviour of superferritic stainless steels cathodically modified with minor additions of ruthenium in sulphuric and hydrochloric acids," Materials and Design, vol. 30, no. 5, pp. 1451-1457, 2009.

[34] S. C. Tjong, J. S. Ku, and N. J. Ho, "Laser surface alloying of ferritic Fe-40Cr alloy with ruthenium," Surface and Coatings Technology, vol. 90, no. 2, pp. 203-209, 1997.

[35] G. N. Kustova, Y. A. Chesalov, L. M. Plyasova, I. Y. Lin, and A. I. Nizovskii, "Vibrational spectra of $\mathrm{WO}_{3} \cdot \mathrm{nH}_{2} \mathrm{O}$ and $\mathrm{WO}_{3}$ polymorphs," Vibrational Spectroscopy, vol. 55, no. 2, pp. 235240, 2011.

[36] K. Nonaka, A. Takase, and K. Miyakawa, "Raman spectra of sol-gel-derived tungsten oxides," Journal of Materials Science Letters, vol. 12, no. 5, pp. 274-277, 1993. 

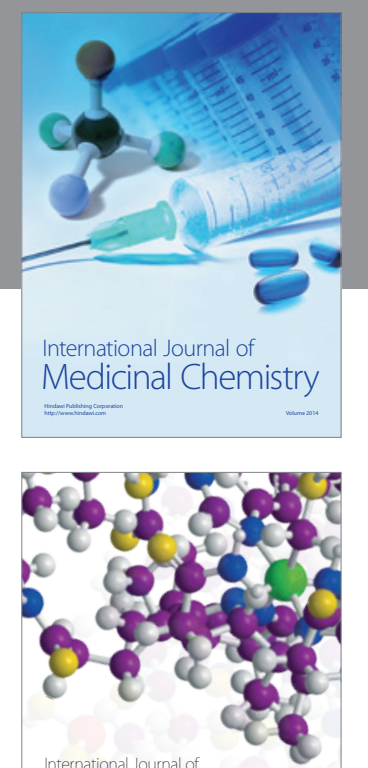

\section{Carbohydrate} Chemistry

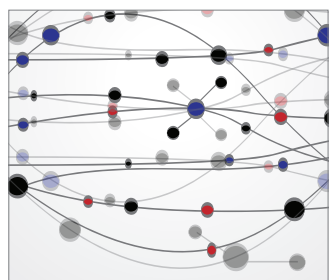

The Scientific World Journal
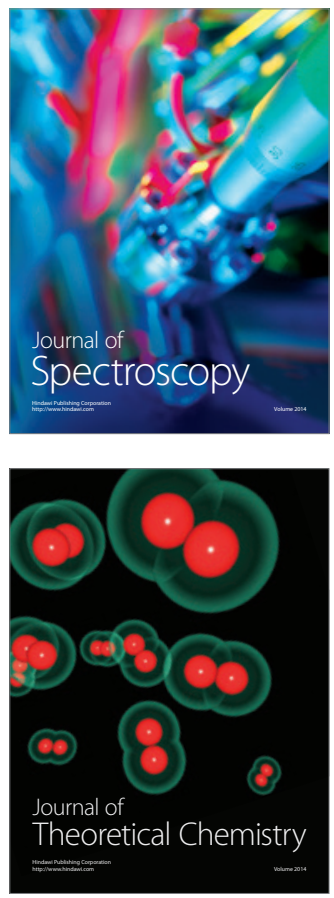
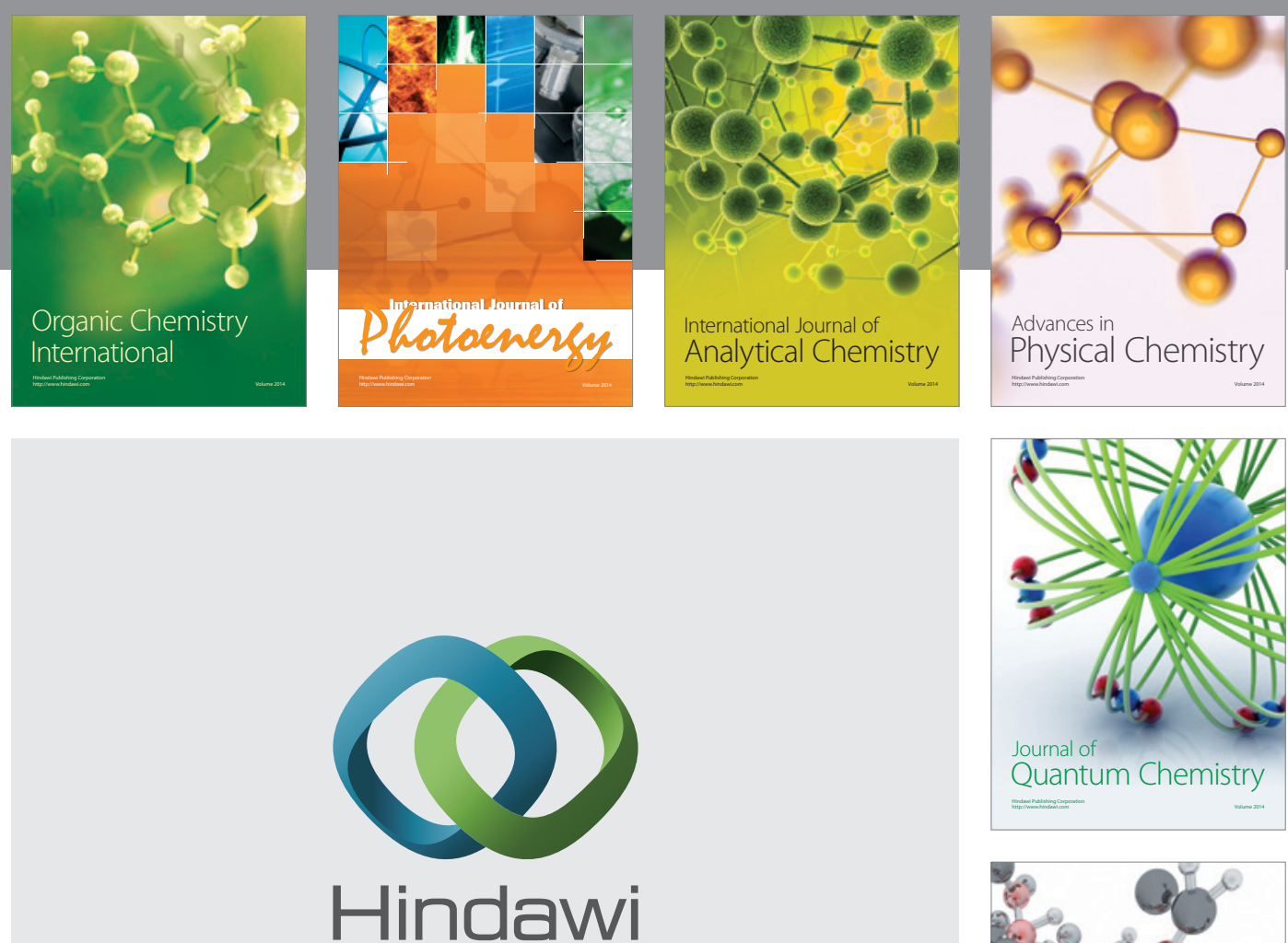

Submit your manuscripts at

http://www.hindawi.com

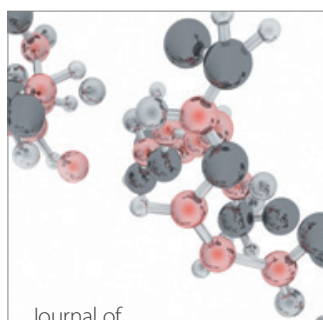

Analytical Methods

in Chemistry

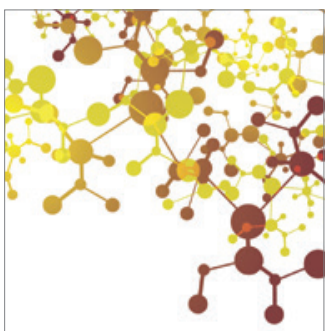

Journal of

Applied Chemistry

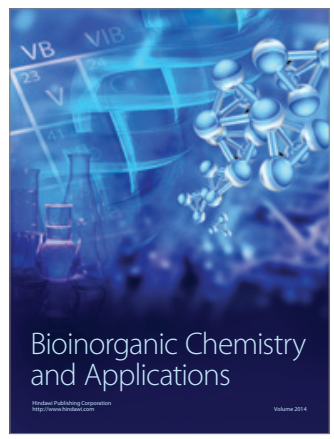

Inorganic Chemistry
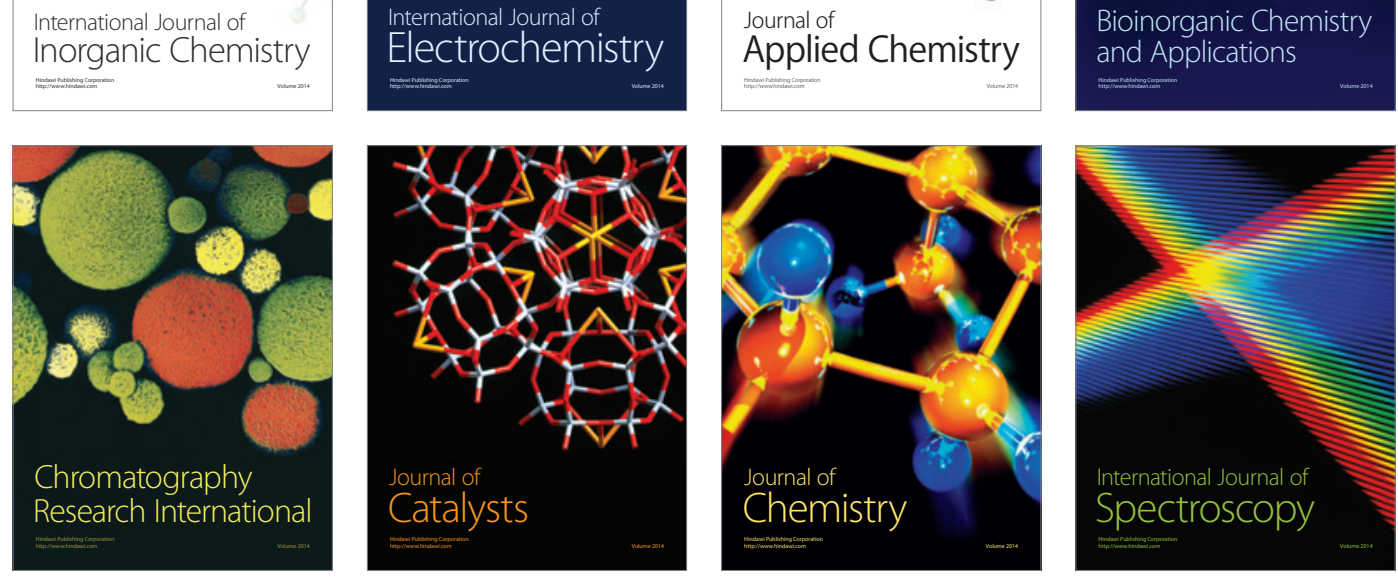